\title{
EM LEGÍTIMA DEFESA: a escrita feminina negra como enfrentamento e transgressão
}

Marisangela Lins de Almeida

Resumo

Como apontou Sueli Carneiro (2018), a violência perpetrada pela naturalização do racismo na sociedade, especificamente brasileira, estabeleceu estereótipos, espaços e não-espaços para nós, mulheres negras, afastando-nos do campo intelectual. Partindo dessa constatação elaboro uma reflexão sobre os modos estruturais que sexismo e racismo atuam na invisibilidade da intelectualidade de mulheres negras. A partir das vozes feministas negras insurgentes de intelectuais brasileiras e estadunidenses, como Sueli Carneiro, bell hooks, Lélia Gonzalez e Patrícia Hill Collins problematizo a construção histórica de espaços naturalizados como de ausência (campo intelectual) e de presença (mulata, doméstica e mãe preta) e o penoso processo de transgressão destes.

Palavras-chave: intelectuais negras; transgressão; violência epistêmica

IN SELF-DEFENSE: black female writing as a confrontation and transgression

\begin{abstract}
As pointed out by Sueli Carneiro (2018), the violence perpetrated by the naturalization of racism in society, specifically Brazilian, established stereotypes, spaces and non-spaces for us, black women, moving away from the intellectual field. Based on this observation I elaborate a reflection on the structural ways that sexism and racism act in the invisibility of the intellectuality of black women. From the insurgent black feminist voices of Brazilian and americans intellectuals, such as Sueli Carneiro, bell hooks, Lélia Gonzalez and Patricia Hill Collins, I problematize the historical construction of naturalized spaces as of absence (intellectual field) and presence (mulatto, domestic and black mother) and their painful transgression process.
\end{abstract} Keywords: black intellectuals; transgression; epistemic violence

EN DEFENSA PROPIA: la escritura feminina negra como confrontación y transgresión

Resumen

Como señaló Sueli Carneiro (2018), la violencia perpetrada por la naturalización del racismo en la sociedad específicamente brasileña estableció estereotipos, espacios y no espacios para nosotras las mujeres negras, alejándonos del campo intelectual. Con base en esta observación detallo las formas estructurales en que el sexismo y el racismo actúan en la invisibilidad de la intelectualidad de las mujeres negras. Desde las voces feministas negras insurgentes de intelectuales brasileñas y estadunidenses como Sueli Carneiro, bell hooks, Lélia Gonzalez y Patricia Hill Collins cuestiono la construcción histórica de espacios naturalizados como ausencia (campo intelectual) y presencia (mulata, empleada domestica y madre negra) y su doloroso proceso de transgresión.

Palabras clave: intelectuales negros; transgresión; violencia epistémica. 


\section{A INVISIBILIDADE DA ESCRITA FEMININA NEGRA}

Quem nos deu permissão para praticar o ato de escrever? Por que escrever parece tão artificial para mim? Eu faço qualquer coisa para adiar este ato - esvazio o lixo, atendo o telefone. Uma voz é recorrente em mim: Quem sou eu, uma pobre chicanita do fim do mundo, para pensar que poderia escrever? Como foi que me atrevi a tornar-me escritora enquanto me agachava nas plantações de tomate, curvando-me sob o sol escaldante, entorpecida numa letargia animal pelo calor, mãos inchadas e calejadas, inadequadas para segurar a pena? Como é difícil para nós pensar que podemos escolher tornar-nos escritoras, muito mais sentir e acreditar que podemos! O que temos para contribuir, para dar? Nossas próprias expectativas nos condicionam. Não nos dizem a nossa classe, a nossa cultura e também o homem branco, que escrever não é para mulheres como nós? (ANZALDÚA, 2000, p. 230)

Quem tem autoridade para pensar, escrever e teorizar? De que modo a intelectualidade é atravessada por relações de gênero, raça e classe? ${ }^{1} \mathrm{Na}$ epígrafe deste texto, Anzaldúa (2000) levanta um questionamento sobre a autoridade do ato de pensar e escrever, denunciando que a prática da escrita e o próprio campo do conhecimento e da intelectualidade orientam-se em cânones eurocêntricos, excluindo mulheres não brancas.

Com base nesse debate, elaboro uma reflexão teórica conduzida por intelectuais negras brasileiras e estadunidenses, e a partir dessas autoras problematizo - partindo da perspectiva de que o conhecimento é marcado geo-historicamente e está relacionado à diferença colonial ${ }^{2}$, como apontou Mignolo (2003) - as nuances da invisibilidade do pensamento feminista negro e do afastamento, construído historicamente, entre mulheres negras e o campo intelectual.

No texto a seguir, Conceição Evaristo (2018) questiona a invisibilidade da produção teórica e literária de mulheres negras, manifestando e denunciando o atraso do seu reconhecimento no campo literário e, consequentemente, de sua obra Becos da Memória.

Que regras são essas da sociedade brasileira para vermos uma mulher virar um expoente no campo da literatura só aos 71 anos? Enquanto você vê outras expoentes na literatura que às vezes são meninas com idade para serem minha neta, mas como vêm de um grupo social diferenciado do meu, são mais jovens, são brancas, têm sua competência logo revelada? Por que a minha competência está sendo tão tardiamente reconhecida? [...] É preciso questionar essas regras e dinâmicas sociais, culturais e econômicas que tornam tudo muito mais difícil para as pessoas negras. A primeira obra que eu escrevi, Becos da Memória, ficou guardada durante 20 anos. Eu mandei para várias editoras. O texto literário, no caso da autoria negra, carrega a nossa subjetividade na própria narrativa. A temática negra, principalmente quando trabalha com identidade negra, não é muito bem aceita. Quando a temática negra trata do folclore, ou não é tão reivindicativa, aí interessa. Mas quando questiona as próprias relações raciais no Brasil, é quase um tema interdito. Principalmente se isso é colocado pela própria autoria negra. Até então, os brancos podiam dizer a nosso respeito. Mas quando a gente se apropria do nosso discurso, da nossa história, isso é motivo de

\footnotetext{
${ }^{1}$ Uma versão resumida desse texto foi apresentada no XVIII Encontro de História da Anpuh - Rio de Janeiro, em jul. 2018.

${ }^{2}$ Quijano (1989), ao teorizar a respeito do conceito de colonialidade do poder, denuncia que, mesmo após a destruição do colonialismo, há uma continuidade das relações de colonialidade. Já Mignolo (2003) argumenta que a matriz colonial do poder é atravessada pelos eixos entrelaçados de controle: da economia, da autoridade, da sexualidade e do gênero, da natureza e dos seus recursos, da subjetividade e do conhecimento. Assim, segundo ele, a colonialidade se reproduz numa tripla dimensão: do poder, do saber e do ser.
} 
interdição. (CONCEIÇÃO EVARISTO, entrevista concedida a Júlia Dias Carneiro, BBC Brasil RJ, mar. 2018)

Conceição Evaristo nasceu na década de 1940 numa favela da zona Sul de Belo Horizonte, Minas Gerais. Filha de uma lavadeira que, assim como Carolina Maria de Jesus, mantinha um diário onde anotava as dificuldades de um cotidiano sofrido. Conceição cresceu rodeada por palavras. Teve que conciliar os estudos com o trabalho como empregada doméstica, até concluir o curso normal, em 1971, já aos 25 anos. Na atualidade, Conceição Evaristo é uma das principais expoentes da literatura brasileira e afro-brasileira, e tornou-se também uma escritora e intelectual negra de projeção internacional, com livros traduzidos em outros idiomas.

A autora traz em sua literatura profundas reflexões acerca das questões de raça e de gênero, com o objetivo claro de revelar a desigualdade velada em nossa sociedade, de recuperar uma memória sofrida da população afro-brasileira em toda sua riqueza e sua potencialidade de ação.

Conceição Evaristo usa a expressão escrevivências para falar na sua escrita feita a partir de suas vivências como mulher, negra, de origem pobre. Por meio de suas perspectivas - marcadas, como não poderia deixar de ser, pela vivência de ser mulher negra na sociedade brasileira contribui para a constituição de uma história brasileira sob a perspectiva feminina negra que revela elementos apagados e/ou desprivilegiados pela escrita masculina e branca.

Para adentrar o campo acadêmico, acessar o universo científico e ser reconhecida como intelectual, as mulheres enfrentam interdições por questões de gênero ${ }^{3}$. No caso das mulheres negras e não brancas, essas interdições estão fundamentadas também na raça. Como aponta Conceição Evaristo, acessar o campo intelectual e ter visibilidade é transgredir ${ }^{4}$ fronteiras, transpor obstáculos. Diante disso, um questionamento importante a se fazer é: de que modo as representações sociais e culturais das mulheres negras atuam nessa interdição?

Para bell hooks (1995), os corpos femininos negros são representados de duas formas: a) marcados pelo estereótipo da mãe preta; b) representações dos corpos das mulheres negras como selvagens, sexuais e desqualificados.

Sobre o estereótipo da mãe preta:

$\mathrm{Na}$ idade adulta passei anos julgando (e por isso fazendo com que fosse) importante para mim terminar qualquer outra tarefa por mais inconsequente que pudesse ser para só depois me dedicar ao trabalho intelectual. Claro, muitas vezes eu chegava no espaço destinado a esse trabalho cansada, exausta e sem energia. A socialização sexista inicial que ensina às negras e na verdade a maioria das mulheres que o trabalho mental tem de ser sempre secundário aos afazeres domésticos, ao cuidado dos filhos ou a um monte de outras atividades servis, tornou difícil para elas fazer do trabalho intelectual uma prioridade essencial mesmo quando suas circunstâncias sociais ofereciam de fato recompensas por essa atividade (hooks, 1995, p. 471).

\footnotetext{
${ }^{3}$ Sobre os aspectos relacionados às mulheres brancas e à educação feminina, ver Rosemberg (2012). Apesar de não trazer o recorte de raça, a autora historiciza o processo brasileiro da educação das mulheres, ressaltando que, no Brasil, isso é um fato marcado por um percurso lento e acidentado. A pesquisadora demonstra que índices de analfabetismo são datados e que marcaram historicamente a vida das mulheres brasileiras.

${ }^{4}$ Devemos, então, pensar a ideia de transgressão: o termo "transgressão" vem do latim gradior, que significa andar, marchar. Quando transformamos o verbo gradior no substantivo, aparece a palavra gradus, que significa escada, salto, nível. Daí deriva graus, graduar, degradar, regressar, ingressar e transgredir, sendo que todos esses termos contêm a ideia de romper um limite. Transgredir, dessa forma, significa "infringir, quebrar ou desobedecer uma ordem, uma lei, uma norma, um costume. Ou seja, é a ação humana de atravessar, ultrapassar, noções que pressupõem a existência de uma norma que estabelece e demarca limites" (PIRES, 2017).
} 
É bem verdade que nós, mulheres, em especial as negras e pobres, fomos educadas para o trabalho e servir, ou seja, para reforçar o paradigma da mãe preta. As tarefas domésticas sempre vieram em primeiro lugar. Durante a infância, não havia tempo para o exercício do pensar. $\mathrm{O}$ trabalho intelectual exige um distanciamento, um isolamento; escrever é uma atividade solitária, e para nós, que fomos criadas em meio a um grupo que valoriza o trabalho não intelectual em detrimento do trabalho intelectual, é extremante difícil, como apontou hooks (1995).

Por outro lado, as representações globais do corpo das negras nos meios de comunicação de massa contemporâneos continuam a nos identificar como mais sexuais, como aberrações primitivas descontroladas.

Para bell hooks (1995, p. 468):

[...] Dentro do patriarcado capitalista com supremacia branca, toda a cultura atua para negar às mulheres a oportunidade de seguir uma vida da mente, torna $\mathrm{O}$ domínio intelectual um lugar interdito. Como nossas ancestrais do século XIX só através da resistência ativa exigimos nosso direito de afirmar uma presença intelectual. O sexismo e o racismo atuando juntos perpetuam uma iconografia de representação da negra que imprime na consciência cultural coletiva a ideia de que ela está neste planeta principalmente para servir aos outros. Desde a escravidão até hoje o corpo da negra tem sido visto pelos ocidentais como o símbolo de uma presença feminina natural orgânica mais próxima da natureza animalística e primitiva [...] mais que qualquer grupo de mulheres nesta sociedade as negras têm sido consideradas somente corpo sem mente. A utilização de corpos femininos negros na escravidão como incubadoras para a geração de outros escravos era a exemplificação prática da ideia de que as mulheres desregradas deviam ser controladas. Para justificar a exploração masculina branca e o estupro das negras durante a escravidão, a cultura branca teve de produzir uma iconografia de corpos de negras que insistia em representá-las como altamente dotadas de sexo, a perfeita encarnação de um erotismo primitivo e desenfreado. Essas representações incutiram na consciência de todos a ideia de que as negras eram só corpo sem mente. A aceitação cultural dessas representações continua a informar a maneira como as negras são encaradas. Vistas como símbolo sexual os corpos femininos negros são postos numa categoria em termos culturais tida como bastante distante da vida mental.

No Brasil, a transgressão de mulheres intelectuais negras principia com a transposição de lugares preestabelecidos socialmente. O racismo estrutural está no cerne da invisibilidade da intelectualidade das mulheres negras, pois efeitos da hegemonia branca no imaginário social atuam sobre a acepção do que é ser mulher negra, agente de produção intelectual.

Logo, a combinação de racismo e sexismo perpetuam violências silenciosas que agem historicamente, desenhando o campo intelectual como um não lugar para as mulheres negras. $\mathrm{O}$ lugar social naturalizado da mulher negra está relacionado ao trabalho doméstico e sexual, imbricado também pela ideia de incapacidade intelectual.

Segundo Lélia Gonzalez (1984), intelectual negra brasileira, há um imaginário social que associa mulheres negras à mulata, doméstica ou mãe preta. Suas discussões são atravessadas por questionamentos a respeito da naturalização do racismo, ditadas por meio de construções culturais estereotipadas de indolência, malandragem e da incapacidade intelectual da(o) negra(o). Logo, estereótipos sexistas e racistas imprimem na consciência coletiva aspectos de sujeição e objetificação sexual, representações que marcam a vida de mulheres negras desde a infância.

Como afirmou hooks (1995), a atuação interativa do sexismo e do racismo perpetuam uma iconografia de representação da mulher negra que imprime na consciência cultural coletiva a ideia de que ela está neste mundo principalmente para servir aos outros. Segundo a intelectual, desde a 
escravidão até hoje, o corpo da negra tem sido visto pelos ocidentais como o símbolo de uma presença feminina natural orgânica, mais próxima da natureza animalística e primitiva, o que implica uma leitura social da mulher negra como um corpo sem mente.

Ora, essa concepção sexista e racista torna o domínio intelectual um lugar de obstáculos, mas também de transgressões.

Gonzalez (1984) nos proporciona importante reflexão sobre as formas específicas como as mulheres negras são afetadas pelo racismo e sexismo. A partir de estereótipos sociais estruturais, a intelectual discute os efeitos violentos dessas imbricações para as mulheres negras no contexto brasileiro. A representação das mulheres negras na sociedade brasileira passa pela objetificação sexual de seus corpos. Isso é problematizado pela autora a partir da noção de mulata e de estereótipos sociais internalizados e reproduzidos no carnaval brasileiro. Segundo a autora, é no carnaval que o mito da democracia racial é reencenado e exaltado. O mito da democracia racial, para além do que mostra, oculta algo, "[...] pois o outro lado do endeusamento carnavalesco ocorre no cotidiano dessa mulher, no momento em que ela se transfigura na empregada doméstica" (GONZALEZ, 1984, p. 228). Assim sendo, mulata e doméstica pode ser atribuição de um mesmo sujeito, a nomeação dependerá da situação específica.

O que explica a situação da doméstica ser o lado oposto da exaltação é o fato de que a leitura social da mulher negra como doméstica está no cotidiano. Gonzalez (1984) aponta que é a partir da figura da mucama que se engendram noções de mulata e doméstica. Essas são cruzadas, na história cultural brasileira, por questões sexuais ocultadas / silenciadas, mas ainda fortemente presentes e vivenciadas.

O que Gonzalez (1984) denuncia é que na modernidade há uma reedição das funções escravocratas de trabalho e sexuais das mulheres negras, principalmente no que diz respeito às mais pobres. Discutindo o conceito de lugar natural, ela aponta para a divisão racial do espaço físico, que reserva à população negra condições precárias de moradia, saúde, além do encarceramento em massa e do genocídio.

A partir de sua análise, a intelectual aponta a construção brasileira de ocultamentos e negações do racismo. A exaltação do mito da democracia racial, externalizada, vendida e comprada pelo carnaval, reforça a ideia de harmonia entre brancos e negros durante o restante do ano. Isso leva a uma negação dos aspectos estruturais racistas no país e a um reconhecimento (inclusive internacional) estereotipado sobre a população brasileira no geral, e das mulheres negras em particular, visto que são objetificadas. Sendo assim, a intelectualidade, um espaço socialmente marcado como branco e eurocêntrico, historicamente negou-nos a autoridade do saber. As representações sociais construídas sobre as mulheres negras, como visto, autoriza uma leitura social de não racionalidade.

Assim, adentrar no campo intelectual exige transgredir fronteiras materiais e simbólicas. Nesse sentido, penso que um questionamento precisa ser levantado: qual o lugar das mulheres negras na construção de um discurso de resistência no contexto pós-colonial?

Collins (2016), teorizando a partir da academia e do contexto das mulheres afro-americanas, argumenta que, mesmo em ocupação acadêmica marginal, muitas intelectuais negras têm feito uso criativo de sua marginalidade, do seu status de outsider within (forasteiras de dentro), para produzir um pensamento feminista negro capaz de refletir um ponto de vista especial em relação ao self, à família e à sociedade.

Para Collins (2016, p. 100) "[...] muitas intelectuais negras, especialmente aquelas em contato com sua marginalidade em contextos acadêmicos, exploram esse ponto de vista produzindo análises distintas quanto às questões de raça, classe e gênero". Ou seja, é a partir de suas condições de marginalidade social e acadêmica que as mulheres negras teorizam e essa postura 
crítica é essencial para produzir deslocamentos no conceito de intelectualidade baseado em cânones eurocêntricos.

Para hooks (1995, p. 468), é o conceito ocidental sexista e racista de intelectual que impossibilita lermos as mulheres negras como representativas de uma vocação intelectual. Assim, discutindo a respeito da definição de intelectual, hooks (1995) assinala a imbricação da intelectualidade com a ação da transgressão discursiva.

Há, em nossa sociedade, uma construção social que associa o exercício da intelectualidade com sujeitos brancos, do sexo masculino e alocado numa classe social alta. Esse perfil do que é um intelectual, entre outros aspectos que discutiremos mais adiante, inibe a leitura social das mulheres negras como intelectuais.

Essas fronteiras podem ser problematizadas a partir do movimento feminista, o que veremos a seguir.

\section{ENEGRECENDO O FEMINISMO: FEMINISMOS E INTELECTUALIDADES}

[...] aqueles homens ali dizem que as mulheres precisam de ajuda para subir em carruagens, e devem ser carregadas para atravessar valas, e que merecem o melhor lugar onde quer que estejam. Ninguém jamais me ajudou a subir em carruagens, ou a saltar sobre poças de lama, e nunca me ofereceram melhor lugar algum! $\mathrm{E}$ não sou uma mulher? Olhem para mim? Olhem para meus braços! Eu arei e plantei, e juntei a colheita nos celeiros, e homem algum poderia estar à minha frente. E não sou uma mulher? Eu poderia trabalhar tanto e comer tanto quanto qualquer homem - desde que eu tivesse oportunidade para isso - e suportar o açoite também! E não sou uma mulher? Eu pari cinco filhos e vi a maioria deles ser vendida para a escravidão, e quando eu clamei com a minha dor de mãe, ninguém a não ser Jesus me ouviu! E não sou uma mulher? Daí eles falam dessa coisa na cabeça; como eles chamam isso... [alguém da audiência sussurra, "intelecto"]. É isso querido. O que é que isso tem a ver com os direitos das mulheres e dos negros? Se o meu copo não tem mais que um quarto, e o seu está cheio, por que você me impediria de completar a minha medida? [...] agradecida a vocês por me escutarem, e agora a velha Sojourner não tem mais nada a dizer. (TRUTH, Sojourner. Discurso proferido como intervenção na Women's Rights Convention, em Ohio, Estados Unidos, em 1851).

Não ao acaso elegi o discurso de Sojourner Truth ${ }^{5}$ para iniciar as discussões sobre a relação da intelectualidade negra e a universalidade do feminino na teoria feminista clássica. As fortes e sábias palavras de Truth, ainda na metade do século XIX, evidenciavam o problema que as feministas negras que a sucederam também enfrentariam: a universalização da categoria mulher. Além disso, apontam aspectos do espinhoso percurso da intelectualidade das mulheres negras.

Essas duas problemáticas levantadas por Truth orientarão as posteriores reflexões desse texto. Assim, Truth nos ensina muito sobre a transgressão de fronteiras intelectuais. Dessa forma, operar com dinâmicas de intelectualidades de sujeitos subalternizados é constatar silêncios, mas é também mapear falas insurgentes.

Segundo hooks (1995), tratando do contexto norte-americano, muito pouco se escreveu sobre intelectuais negras, apesar do testemunho histórico de que as negras sempre desempenharam um papel importante como professoras, pensadoras críticas e teóricas culturais da vida negra e em particular nas comunidades negras segregadas.

\footnotetext{
${ }^{5}$ Sojourner nasceu escravizada em Nova Iorque e tornou-se livre em 1787. Foi uma abolicionista afro-americana e ativista dos direitos das mulheres.
} 
Assim: um saber fundamentado num ponto de vista das mulheres não brancas levará adiante uma prática intelectual emancipatória? O que fundamenta um saber feminista negro?

Collins (2016) argumenta que a postura crítica de intelectuais negras marginais é essencial para gerar um ponto de vista diferente em relação aos paradigmas sociais. Ou seja, enquanto sujeitos de saber, essas intelectuais questionam as bases das verdades epistemológicas, inclusive do pensamento feminista dito universal, branco e com bases eurocêntricas.

Segundo Collins (2016, p. 101) é a própria condição de "marginalidade" intelectual e material que estimula a criatividade intelectual. Essa combinação estrutura a produção de um pensamento feminista negro, que "[...] consiste em ideias produzidas por mulheres negras que elucidam um ponto de vista de e para mulheres negras".

Enfim, é notável o compromisso de intelectuais negras com uma plataforma política feminista que esteja articulada a um projeto mais amplo de sociedade democrática e socialmente justa. Plataforma que incorpora uma diversidade de feminismos, que as mulheres negras vêm sinalizando para iniciativas fundamentais nas interações entre racismo e sexismo.

No caso brasileiro, Sueli Carneiro (2003) situa os avanços históricos do movimento feminista, entretanto, denuncia a visão eurocêntrica do movimento e o caráter universalizante da categoria mulher, incapaz de reconhecer as diferenças e desigualdades presentes no universo feminino. A autora aponta, como consequência, o silenciamento de vozes de mulheres que sofrem outras formas de opressão além do sexismo. Para Sueli Carneiro (2003), a dimensão dessa problemática fez com que houvesse a necessidade de reelaboração do discurso e das práticas do feminismo, traduzido na perspectiva do movimento de mulheres negras no Brasil.

Sueli Carneiro (2003) propõe a necessidade de enegrecer o feminismo, expressão utilizada para designar a trajetória das mulheres negras no movimento feminista brasileiro pois, segundo ela, as mulheres negras tiveram uma experiência histórica diferenciada que o discurso clássico sobre a opressão das mulheres não tem reconhecido, assim como não tem dado conta da diferença qualitativa que o efeito da opressão sofrida teve e tem na identidade feminina negra.

Essa problemática é central no posicionamento teórico-político de Sueli Carneiro, que evidencia, de forma irrefutável, aspectos das diferentes experiências históricas entre mulheres brancas e negras.

Quando falamos do mito da fragilidade feminina, que justificou historicamente a proteção paternalista dos homens sobre as mulheres, de que mulheres estamos falando? Nós, mulheres negras, fazemos parte de um contingente de mulheres, provavelmente majoritário, que nunca reconheceram em si mesmas esse mito, porque nunca fomos tratadas como frágeis. Fazemos parte de um contingente de mulheres que trabalharam durante séculos como escravas nas lavouras ou nas ruas, como vendedoras, quituteiras, prostitutas... [...] fazemos parte de um contingente de mulheres com identidade de objeto. Ontem, a serviço de frágeis sinhazinhas e de senhores de engenho tarados. São suficientemente conhecidas as condições históricas nas Américas que construíram a relação de coisificação dos negros em geral e das mulheres negras em particular [...]. Quando falamos em romper com o mito da rainha do lar, da musa idolatrada dos poetas, de que mulheres estamos falando? As mulheres negras fazem parte de um contingente de mulheres que não são rainhas de nada, que são retratadas como antimusas da sociedade brasileira, porque o modelo estético de mulher é a mulher branca. Quando falamos em garantir as mesmas oportunidades para homens e mulheres no mercado de trabalho, estamos garantindo emprego para que tipo de mulher? Fazemos parte de um contingente de mulheres para as quais os anúncios de emprego destacam a frase: "Exige-se boa aparência" (CARNEIRO, 2003, p. 12). 
Problematizando questões referentes ao mito da fragilidade feminina e relações de trabalho, Carneiro (2003) enfatiza que essas experiências devem ser pensadas de forma diferenciada entre mulheres brancas e negras, pois essas mulheres vivenciam o sexismo de forma diferente, são atingidas também pelo racismo e outras formas de discriminação, criando, portanto, uma associação de sistemas múltiplos e interseccionais de discriminação.

Crenshaw (2012), responsável pelo desenvolvimento teórico do conceito de interseccionalidade, aborda a problemática estrutural das intersecções da discriminação de raça e gênero, buscando compreender como elas operam juntas e possuem efeitos materiais sobre a vida de mulheres negras.

A interseccionalidade, compreendida enquanto expressão e resultado de práticas políticas e desenvolvimento teórico de intelectuais ligadas ao feminismo negro norte-americano, pode ser compreendida enquanto projeto de conhecimento e ferramenta política para a superação das desigualdades que mulheres negras enfrentam.

Segundo Crenshaw (2012), é preciso identificar o que acontece quando diversas formas de opressão se combinam e afetam a vida de pessoas específicas. Problematizando a expressão discriminação interseccional, a intelectual demonstra preocupação com a desproteção das mulheres negras frente às leis e políticas públicas, pois nem sempre estas preveem a dupla faceta de mulher e negra. Assim, a interseccionalidade é pensada pela autora como uma ponte entre a experiência, algo que é vivenciado na prática e as políticas públicas; essa ponte também ligaria as questões de raça e gênero, uma vez que parte do projeto interseccional visa incluir questões raciais nos debates de gênero e direitos humanos e questões de gênero nos debates raciais.

Para além do problema da discriminação interseccional em si, há a invisibilidade dessa discriminação dentro dos movimentos políticos, pois mesmo no interior dos movimentos feministas e antirracistas, raça e gênero são vistos como questões excludentes, não dialógicas. Nesse sentido, pensar movimentos separadamente torna as mulheres negras invisíveis e suas demandas específicas podem ficar subincluídas.

De acordo com Crenshaw (2012), muitas questões que afetam especificamente as mulheres negras não são incluídas na agenda das feministas. Já para Carneiro (2003, p. 2):

Em geral, a unidade na luta das mulheres em nossas sociedades não depende apenas de nossa capacidade de superar as desigualdades geradas pela histórica hegemonia masculina, mas exige, também, a superação de ideologias complementares desse sistema de opressão, como é o caso do racismo.

Crenshaw (2012) e Carneiro (2003) chamam atenção para o fato de que as mulheres não brancas tiveram experiências históricas diferenciadas e que isso precisa ser considerado pelos movimentos políticos feministas e reconhecido pelas políticas públicas, pois o peso combinado das estruturas de raça e das estruturas de gênero marginaliza mulheres que estão na base. Sobre as colisões que afetam as mulheres negras, Crenshaw (2012) aponta três: a discriminação contra grupos específicos; discriminação mista ou composta; e discriminação estrutural.

$\mathrm{Na}$ discriminação mista ou composta as mulheres negras são afetadas pela combinação de duas formas diferentes de discriminação (racial e de gênero). A subordinação estrutural é o resultado de políticas, geralmente interseccionais, que possuem efeitos particulares para as mulheres em decorrência de sua posição na estrutura socioeconômica. Mulheres marginalizadas economicamente são as mais afetadas, e talvez esse modelo de discriminação exemplifique a coalisão entre gênero, raça, globalização e etnia.

Crenshaw (2012) utiliza a expressão experiências de interseccionalidade, referindo-se ao fato de que ser mulher e ser negra não são categorias diferentes e/ou opostas, mas posições coexistentes. Ou seja, é preciso, dentro dos movimentos sociais e do campo das políticas públicas, considerar 
que raça e gênero não são problemas mutuamente excludentes; não considerar esse fato seria contribuir para a invisibilidade interseccional. Dessa forma, a noção de experiência se coloca como questão fundamental, pois é a partir de suas experiências cotidianas e acadêmicas que mulheres negras estão teorizando e produzindo uma epistemologia feminista negra.

A questão da interseccionalidade se colocou para Crenshaw (2012) a partir de uma experiência pessoal - aliás o processo de compreensão do fenômeno da interseccionalidade é marcado também por experiências vivenciadas por outras mulheres negras. A autora ressalta que conheceu algumas dessas mulheres na Conferência Mundial contra o Racismo, em 2001. E desse lugar de invisibilidade é que teoriza.

Voltamos à Conceição Evaristo (2018), que afirma: “[...] quando escrevo, quando invento, quando crio a minha ficção, não me desvencilho de um corpo mulher-negra em vivência”. Em Insubmissas lágrimas de mulheres, obra que reúne 13 contos, as subjetividades das experiências narradas misturam-se e são atravessadas pelas experiências da própria autora. Assim, escrevivência nos remete a uma forma de escrita que é vivência e ao mesmo tempo resistência e memória, memórias de interseccionalidade.

Sobre mulheres não brancas e o ato de escrever, as indagações de Glória Anzaldúa (2000), citada na epígrafe desse texto, nos trazem reflexões sobre quem está autorizado a pensar, escrever, teorizar. Ademais, desvela o fato de que o conhecimento é marcado geo-historicamente.

\section{CONSIDERAÇÕES}

Procurei, ao longo do texto, problematizar questões relacionadas aos estereótipos construídos historicamente, que atravessam temporalidades e se reinventam na modernidade mas, de modo geral, continuam reafirmando lugares e não lugares para nós, mulheres negras. A não intelectualidade do negro, particularmente das mulheres negras, é uma dessas representações.

Ao escrever Eu sei porque o pássaro canta na gaiola, uma de suas autobiografias, Maya Angelou (2018), de modo vívido, tocante e literário, escreve sobre a trajetória da infância de uma menina Negra (no seu livro essa palavra é utilizada com inicial maiúscula), entre os anos de 1930 e 1940. Sua escrita é marcada pelo tom questionador das relações raciais.

Criada pela avó paterna até os 13 anos, no povoado de Stamps, no Arkansas, Sul dos Estados Unidos, Angelou (2018) brilhantemente rememora seu passado, sua infância, de onde observa a conjuntura social, racial e econômica da região. A imagem de homens negros e mulheres negras (catadores de algodão empobrecidos) e suas mãos calejadas pelo trabalho a fazem pensar, ainda na infância, sobre as condições de existência de seu povo. Seus relatos - sensíveis à condição de gênero, raça e classe e seus intercâmbios - manifestam os contornos do cenário da segregação racial nos EUA.

Angelou (2018) relata como a cerimônia de formatura de oitava série, momento ansiado no pequeno povoado, a marcou. Leitora voraz e boa aluna, ela vê suas expectativas frustradas quando o colega Donleavy discursa, expondo a dificuldade dos negros de avançar na carreira científica. Ele diz que alunos brancos teriam a chance de se tornarem Galileus, Madames Curie e Edisons; em contrapartida, garotos negros tentariam ser Jesse Owens e Joe Louis (meninas negras nem entraram na sua conta). Segundo a autora, essas palavras caíram como tijolos no auditório, se acomodaram na sua barriga e fizeram com que a turma de formandos/as de 1940, antes orgulhosa, baixasse a cabeça.

A formatura, o momento mágico e agitado de pregas e presentes e parabéns e diplomas, tinha terminado para mim antes mesmo do meu nome ser chamado. A conquista não era nada. Os mapas meticulosos, coloridos com três cores diferentes, aprender e soletrar palavras decassílabas, decorar todo $\mathrm{O}$ estupro de 
Lucrécia... foi para nada. Donleavy tinha nos exposto. Nós éramos empregadas de fazendeiros, quebra-galhos e lavadeiras, e qualquer coisa maior que aspirássemos ser era uma farsa e presunção (ANGELOU, 2018, p. 204-205).

O atleta Jesse Owens e o pugilista Joe Louis (o Bombardeiro Marrom) eram grandes heróis dos negros na década de 1930 e 1940, entretanto, Angelou (2018) se pergunta quem tinha o direito de decidir que esses dois homens deviam ser os únicos heróis de seu povo. Esses eventos ligados à formatura de oitava série de Maya revelam os perturbadores efeitos do segregacionismo na vida de pessoas negras. Sendo negra e mulher, esses efeitos eram percebidos de forma mais cruel. A autora narra o sentimento de impotência por ser negra e não ter controle sobre sua própria vida. Conta também como "[...] era brutal ser jovem e já estar treinada para ficar sentada em silêncio ouvindo as acusações feitas contra a minha cor sem chance de defesa" (ANGELOU, 2018, p. 205. Grifo nosso).

Angelou encontrou na escrita uma forma de defesa, não somente individual, mas coletiva. A escrita feminista negra constitui uma forma sistemática de defesa. Ao adentrar e teorizar a partir de "espaços" construídos por um imaginário racista e sexista (ciência, intelectualidade, o saber, o pensamento, academia), as mulheres negras agem em legítima defesa, em defesa dos seus.

Desse modo, adentrar no campo acadêmico, lugar por excelência da intelectualidade, é transgredir espaços e agir em legítima defesa. Reafirmo, portanto, a importância de refletir sobre os modos estruturais como o sexismo e o racismo atuam na promoção da invisibilidade do pensamento de mulheres negras no campo intelectual e feminista.

A pergunta evidenciada no título do livro Pode o subalterno falar?, da escritora indiana Gayatri Spivak (2010), é respondida por Gonzalez (1984, p. 225): “[...] o lixo vai falar, e numa boa”. Problematizando a lógica de dominação, a mesma autora aponta para a necessidade de reclamar e assumir a própria fala: "[...] porque o negro é isso que a lógica de dominação tenta (e consegue muitas vezes, nós o sabemos) domesticar? E o risco que assumimos aqui é o do ato de falar com todas as implicações, exatamente porque temos sido falados, infantilizados".

Logo, a intelectualidade feminista negra configura-se num reposicionamento do conhecimento e das mulheres negras na academia e na sociedade.

Por fim, é preciso pensar e repensar nossa posicionalidade no campo da teoria feminista do conhecimento, porque essa teoria fornece parâmetros para problematizarmos melhor questões como as apresentadas aqui nesse texto.

Sardenberg (2002) nos auxilia nesse propósito ao teorizar sobre a ciência moderna e as estratégias epistemológicas que melhor fundamentam um saber feminista. Segundo a autora, historicamente, a ciência moderna negou-nos capacidade e autoridade do saber, produzindo conhecimentos que não atendem nossas necessidades como feministas. A partir de uma instrumentação do gênero, a crítica feminista, expondo a exclusão e invisibilidade das mulheres na ciência, tem avançado no questionamento da própria ciência moderna, pondo em cheque seus pressupostos.

Nesse sentido, o campo feminista apresenta questionamentos sobre neutralidade, objetividade e parâmetros científicos da ciência moderna; sua desconstrução implicaria a construção de uma epistemologia feminista, uma teoria crítica sobre o conhecimento que fundamente um saber politizado. Entre divergências de feministas radicais, socialistas e liberais e questionamentos da crítica pós-moderna sobre a ciência moderna, que se organiza a partir de um sujeito universal (homem branco ocidental) e na dicotomia objetividade (masculina) e subjetividade (feminina) destaco a contribuição da estratégia epistemológica das feministas negras.

Assim, é importante que Sardenberg (2002) tenha apontado questionamentos internos dentro do próprio campo do pensamento feminista, indicando que algumas perspectivas ainda parecem manter uma posição marginal. Ela reconhece as exclusões por meio das quais sujeitos 
feministas são construídos, e utiliza-se dos argumentos de Collins (1990) para pensar os desafios das epistemologias alternativas ao tensionar posturas eurocêntricas.

Aqui postula-se a ideia da combinação de uma epistemologia afrocêntrica e feminista como enfrentamento, quando conceitos de interseccionalidade e outsider within são acionados para tal. A ideia, nesse processo de enfrentamento, propõe um esforço epistemológico de "múltiplas vozes" e, por que não dizer, em legítima defesa.

\section{REFERÊNCIAS}

ANGELOU, Maya. Eu sei por que o pássaro canta na gaiola. Bauru: Astral Cultural, 2018.

ANZALDÚA, Glória. Falando em linguas: uma carta para as mulheres escritoras do terceiro mundo. Florianópolis: Estudos Feministas, 2000.

CARNEIRO, Sueli. Enegrecer o feminismo: a situação da mulher negra na América Latina a partir de uma perspectiva de gênero. In: ASHOKA Empreendedores Sociais; TAKANO Cidadania (orgs.). Racismos contemporâneos. Rio de Janeiro: Takano Editora, 2003.

CARNEIRO, Sueli. Mulheres em movimento. Estudos Avançados, São Paulo, v. 17, n. 49, p. $117-$ 133, 2003.

COLLINS, Patrícia Hill. Aprendendo com a outsider within: a significação sociológica do pensamento feminista negro. Revista Sociedade e Estado, v. 31, n. 1, p. 99-127, jan./abr. 2016.

EVARISTO, Conceição. Entrevista concedida a Júlia Dias Carneiro. BBC Brasil / Rio de Janeiro, mar. 2018.

GONZALES, Lélia. Racismo e sexismo na cultura brasileira. Revista Ciências Sociais Hoje, São Paulo, p. 223-244, 1984.

HOOKS, bell. Intelectuais negras. Estudos feministas, Florianópolis, ano 3, p. 464-478, 2. sem. 1995.

MIGNOLO, Walter. Histórias locais / projetos globais: colonialidade, saberes subalternos e pensamento liminar. Belo Horizonte: Ed. UFMG, 2003.

MOMBAÇA, Jota. Notas estratégicas quanto aos usos políticos do conceito de lugar de fala. Disponível em http://www.buala.org/pt/corpo/notas-estrategicas-quanto-aos-usos-politicos-do-conceito-delugar-de-fala. Acesso em 21 jun. 2018.

PIRES, Luciano. Sobre transgressão. Disponível em http://www.portalcafebrasil.com.br/resumos/582-sobre-transgressao/. Acesso em 16 jun. 2018.

ROSEMBERG, Fúlvia. Mulheres educadas e educação de mulheres. In: PINSKY, Carla Bassanezi; PEDRO, Joana Maria. Nova história das mulheres no Brasil. São Paulo: Contexto, 2012. p. 333-359.

SARDENBERG, Cecília Maria Bacellar. Da crítica feminista à ciência. Uma ciência feminista? In: COSTA, Ana Alice Alcântara; SARDENBERG, Cecília Maria Bacellar (orgs.). Feminismo, ciência e tecnologia. Salvador: Coleção Bahianas, 2002. p. 89-120.

SPIVAK, Gayatri Chakravorty. Pode o subalterno falar? Belo Horizonte: Ed. UFMG, 2010.

Submetido em março de 2020 Aprovado em julbo de 2020 


\section{Informações da autora}

Marisangela Lins de Almeida Universidade Federal de Santa Catarina (UFSC)

E-mail: mary lins 18@hotmail.com

ORCID: https://orcid.org/0000-0002-0850-1577

Link Lattes: http://lattes.cnpq.br/0565403301453162 